\title{
Defective pulmonary innate immune responses post-stem cell transplantation; review and results from one model system
}

\author{
Racquel Domingo-Gonzalez ${ }^{1}$ and Bethany B. Moore ${ }^{2,3}$ * \\ 1 Graduate Program in Immunology, University of Michigan, Ann Arbor, MI, USA \\ ${ }^{2}$ Division of Pulmonary and Critical Care Medicine, Department of Internal Medicine, University of Michigan, Ann Arbor, MI, USA \\ ${ }^{3}$ Department of Microbiology and Immunology, University of Michigan, Ann Arbor, MI, USA
}

\section{Edited by:}

Zoulfia Allakhverdi, University of Montreal, Canada

Reviewed by:

Nicole Baumgarth, University of California Davis, USA

Junji Yodoi, Kyoto University, Japan

*Correspondence:

Bethany B. Moore, University of Michigan, 4053 Biomedical Science Research Building, 109 Zina Pitcher Place, Ann Arbor, MI 48109-2200, USA

e-mail: bmoore@umich.edu
Infectious pulmonary complications limit the success of hematopoietic stem cell transplantation (HSCT) as a therapy for malignant and non-malignant disorders. Susceptibility to pathogens in both autologous and allogeneic HSCT recipients persists despite successful immune reconstitution. As studying the causal effects of these immune defects in the human population can be limiting, a bone marrow transplant (BMT) mouse model can be used to understand the defect in mounting a productive innate immune response post-transplantation. When syngeneic BMT is performed, this system allows the study of BMT-induced alterations in innate immune cell function that are independent of the confounding effects of immunosuppressive therapy and graft-versus-host disease. Studies from several laboratories, including our own show that pulmonary susceptibility to bacterial infections post-BMT are largely due to alterations in the lung alveolar macrophages. Changes in these cells post-BMT include cytokine and eicosanoid dysregulations, scavenger receptor alterations, changes in micro RNA profiles, and alterations in intracellular signaling molecules that limit bacterial phagocytosis and killing. The changes that occur highlight mechanisms that promote susceptibility to infections commonly afflicting HSCT recipients and provide insight into therapeutic targets that may improve patient outcomes post-HSCT.

Keywords: pulmonary complications, hematopoietic stem cell transplantation, eicosanoids, alveolar macrophage, polymorphonuclear leukocytes, scavenger receptors, microRNA, prostaglandins $E$
HEMATOPOIETIC STEM CELL TRANSPLANTATION OVERVIEW Early observations made in the 1950s paved the way for the development of hematopoietic stem cell transplantation (HSCT). Lorenz (1951) showed that animals exposed to radiation could be protected by infusion of bone marrow cells. These studies, together with the previous observation that the deleterious effects of ionizing radiation could be prevented in mice by shielding organs with lead, pushed transplantation forward as a possible therapy for patients suffering from hematologic malignancies (Little and Storb, 2002). HSCT is now used to treat a variety of disorders, including malignant, congenital, and autoimmune disorders (Cutler, 2005; Copelan, 2006).

Prior to receiving a graft, transplant recipients undergo conditioning regimens that include total body irradiation (TBI), chemotherapy, or a combination of TBI and chemotherapy (Aschan, 2007; Passweg, 2012). These regimens subject the recipients' organs, including the lungs, to their cytotoxic effects. The hope is to eradicate the malignant or autoimmune cells and replenish the patient with healthy hematopoietic stem cells (HSCs). If the intensity of the conditioning regimen is myeloablative, repopulation of hematopoietic cells will predominantly come from the donor HSCs (Tomita, 1994; Aschan, 2007). Non-myeloablative conditioning, also known as reduced intensity conditioning (RIC) will allow repopulation from both donor and host HSCs. Depending on the underlying disease, HSCT recipients receive self HSCs (autologous) or HSCs from a human leukocyte antigen (HLA)matched, related, or unrelated donor (allogeneic). A recent study analyzing the global use of transplantation reported that autologous HSCT continues to be more highly implemented than allogeneic transplant (Gratwohl et al., 2010). Although autologous transplant recipients are unlikely to suffer from graft-versus-host disease (GvHD) which arises when the donor leukocytes mount an immune response against different HLA antigens expressed by the host, autologous transplants performed for hematologic malignancies lack the beneficial effects of graft-versus-leukemia $(\mathrm{GvL})$. In the GvL reaction the allogeneic donor HSCs recognize and remove leukemic cells within the host by virtue of the HLA mismatches (Kolb, 2008).

Traditionally, HSCs were aspirated from the bone marrow of donor patients and later infused into recipients. This procedure was often painful for the donor. However, technical advances now allow for mobilization of HSCs into the peripheral blood with the use of the growth factor, granulocyte-colony stimulating factor (G-CSF) (Cutler, 2005; Copelan, 2006). Treatment of donors with G-CSF allows HSCs to be collected with a simple blood draw. Additionally, HSCs can also be harvested from umbilical cord blood 
(Tse, 2008; Peffault de Latour et al., 2013). Each of these techniques has inherent advantages and disadvantages and have been discussed elsewhere (Körbling and Anderlini, 2001; Copelan, 2006; Tse, 2008). RIC has evolved as an alternative to the more traditional myeloablative conditioning regimens for individuals that would have otherwise been unable to undergo transplantation as a therapy due to age, comorbidities, or disorders associated with highrisk non-relapse mortality (Giralt, 2005). Interestingly, despite a reduction in intensity regimens, recipients of RIC HSCT display similar incidence of infectious complications and infection-related mortality (Kim et al., 2013).

\section{PULMONARY COMPLICATIONS}

Although HSCT has become standard care for malignant and non-malignant disorders, its success is significantly limited by the different pulmonary complications that arise following transplantation (Cordonnier, 1986; Griese, 2000; Roychowdhury, 2005; Afessa and Peters, 2006; Copelan, 2006). The engraftment process can be characterized by three distinct phases: the pre-engraftment (0-30 days), early post-engraftment (30-100 days), and late postengraftment phases (beyond 100 days) (Afessa and Peters, 2006; Wingard et al., 2010; Coomes et al., 2011). HSCT recipients are more susceptible to infections prior to engraftment and early after engraftment. During this early time period, the increased susceptibility is mostly due to the incomplete recovery of the immune cell compartment, and is often associated with decreased neutrophil numbers or function (Zimmerli et al., 1991). Although engraftment indicates the transplant was successful in reconstituting hematopoietic cell populations, it is evident that this does not correlate with recovery of an effective immune system, as patients remain susceptible to diverse complications (including infections) long after engraftment occurs (Soubani, 1996; Afessa and Peters, 2006; Coomes et al., 2011). Pulmonary complications, both infectious and non-infectious, have been reported to affect up to $60 \%$ of transplant recipients (Soubani, 1996; Copelan, 2006). Similarly, autopsy studies performed on both allogeneic and autologous transplant recipients revealed pulmonary complication rates of 80-89\% (Roychowdhury, 2005). Although allogeneic transplants have increased incidence of infectious pulmonary complications, this may be attributed, in part, to the use of immunosuppressive therapy required to prevent GvHD. Additionally, GvHD can cause mucosal barrier disruptions which also increase susceptibility to pathogens. Interestingly, however, autologous HSCT recipients also continue to suffer from increased susceptibility to pulmonary infections even though this form of transplant does not require immunosuppressive therapies (Afessa et al., 2012). These observations highlight the inherent dysfunction of the immune response following transplant and suggest that some degree of impaired function is independent of the immunosuppressive therapies or GvHD. The idea that alveolar macrophages (AMs) are inherently less functional post-HSCT is supported by previous observations that AMs obtained from pulmonary lavage of allogeneic HSCT patients late in the post-engraftment phase were functionally defective even in the absence of overt pulmonary infection (Winston et al., 1982). Defects noted in the AMs from these patients included defects in chemotaxis, phagocytosis, and killing of Candida pseudotropicalis as well as phagocytosis and killing of bacteria including Staphylococcus aureus and Listeria monocytogenes. This same study suggested that the defects may be primarily confined to the lung as the function of peripheral blood monocytes in these same assays was similar to control patients (Winston et al., 1982).

Non-infectious complications that arise following transplant include peri-engraftment respiratory distress syndrome (PERDS), diffuse alveolar hemorrhage (DAH), idiopathic pneumonia syndrome (IPS), and bronchiolitis obliterans syndrome (BOS) (Soubani, 1996; Afessa, 2001; Roychowdhury, 2005; Afessa and Peters, 2006; Soubani and Uberti, 2007; Afessa et al., 2012). These occur throughout the different engraftment phases but BOS in particular, is more commonly seen late post-engraftment (Soubani and Uberti, 2007). Malignant relapse or secondary malignancy also complicate successful transplants (Copelan, 2006; Roziakova, 2011). Many times the non-infectious complications can manifest in conjunction with infectious complications (Metcalf et al., 1994; Roychowdhury, 2005). Additionally, infections are risk factors for development of some forms of non-infectious lung injury which may occur later, such as IPS (Versluys, 2010). Importantly, infections with bacterial, viral, and fungal pathogens can afflict both allogeneic and autologous HSCT recipients at multiple times post-transplant (Afessa and Peters, 2006; Lim, 2006).

Viral infections are common in HSCT patients. Cytomegalovirus (CMV) infections predominate in the late phase of engraftment and are associated with increased mortality (Boeckh, 2003, 2011; Kotloff et al., 2004). The advent of prophylactic and antiviral therapy usage has proven to be beneficial in limiting infection in HSCT patients; however, CMV can be particularly difficult to detect and treat (Boeckh, 2011). One autopsy study revealed that $65 \%$ of CMV infections were not diagnosed ante mortem, thus highlighting the frequency of missed detection (Chandrasekar, 1995). Thus, HSCT patients are highly susceptible to CMV as well as other herpesviruses (Soubani et al., 1996; Ljungman, 2002; Marr, 2012). Fungal pathogens are one of the major causes of significant morbidity and mortality in HSCT recipients (Marr et al., 2002). Prior to the use of azole-based anti-fungal prophylaxis, Candida spp. were the leading fungal pathogen following HSCT (Asano-Mori, 2010). However, following implementation of this anti-fungal prophylactic treatment, Aspergillus spp. have become the predominant fungal pathogen causing invasive fungal infections in the lung of both autologous and allogeneic HSCT populations (Bow, 2009; Asano-Mori, 2010). When considering bacterial infections, a shorter time to engraftment and the use of broad-spectrum antibiotics have improved the incidence of bacterial infections, specifically Gram-negative bacteria (Cruciani, 1996; Therriault, 2010). However, bacterial pneumonias remain a significant cause of mortality in this immunocompromised population (Therriault, 2010; Marr, 2012). Pseudomonas aeruginosa (a Gram-negative bacteria) is the most common pathogen isolated within 100 days post-engraftment and is associated with high recurrence rates due to increasing antibiotic resistance (Hakki et al., 2007). Streptococcus pneumoniae is the leading Gram-positive bacterial infection in HSCT recipients, and together with another Gram-positive agent, $S$. aureus, afflicts patients in the late post-engraftment phase and causes significant mortality (Chen et al., 2003; Marr, 2012). 


\section{ANIMAL MODELING}

Murine bone marrow transplant (BMT) models for both syngeneic (genetically identical donor) and allogeneic (non-identical) transplantation offer the opportunity to study changes in the pulmonary immune system and microenvironment following transplantation. In these systems, donor cells are harvested from the femur and tibia of genetically inbred mice and introduced into lethally irradiated syngeneic or allogeneic mice to reconstitute ablated hematopoietic compartments. In order to force reconstitution of myeloid cells from hematopoietic donors, myeloablative conditioning is employed. This can be done via TBI or via chemotherapy regimens. One note of caution however, is that different strains of mice have differing susceptibilities to TBI dosage. For instance, in our laboratory we routinely use $13 \mathrm{~Gy}$ split dose of TBI to myeloablate C57Bl/6 mice and only $10 \mathrm{~Gy}$ for the same purpose in Balb/c mice. Addition of splenic $\mathrm{T}$ cells along with the donor bone marrow inoculum can hasten reconstitution in syngeneic transplants (Ojielo et al., 2003) and can be a source of alloreactive $\mathrm{T}$ cells in models of allogenic BMT hoping to study GvHD or graft versus leukemia responses ( Reddy et al., 2005; Kato et al., 2010).

Studies comparing conditioning regimens for their ability to reconstitute AMs in recipient syngeneic BMT mice showed that both dual-chemotherapy regimens ( 4 days of $25 \mathrm{mg} / \mathrm{kg}$ busulfan followed by 2 days of $100 \mathrm{mg} / \mathrm{kg}$ cyclophosphamide) and $13 \mathrm{~Gy}$ TBI regimens induced greater than $50 \%$ reconstitution of AMs and spleen cells from donor stem cells by week 5 post-BMT (Hubbard et al., 2008). Thirteen Gray TBI, when compared to dual-chemotherapy, was the more effective conditioning regimen. With 13 Gy TBI conditioning, donor reconstitution, measured by the percentage of CD45.1 donor cells in CD45.2 recipient mice, was observed at $82 \pm 2 \%$ in $\mathrm{AMs}$ and $95 \pm 1 \%$ in spleen cells (Hubbard et al., 2008). The percentages of donor-derived AMs and spleen cells with dual-chemotherapy were $56 \pm 6.2$ and $72.3 \pm 2.1 \%$ (Hubbard et al., 2008). Similar defects in host immune responses were noted in all of these myeloablative conditioning regimens regardless of whether $T$ cells were included in the original inoculum (Hubbard et al., 2008).

\section{DEFECTIVE PULMONARY INNATE IMMUNITY TO BACTERIA BACTERIAL INFECTION MODEL}

Despite the use of antibiotic prophylaxis, infectious pulmonary complications continue to afflict both autologous and allogeneic HSCT recipients throughout the process of engraftment and well into the late post-engraftment phase ( $>100$ days) (Chen et al., 2003; Marr, 2012). Although reported to predominantly manifest in the pre-engraftment and early post-engraftment phases, $P$. aeruginosa-driven pneumonia is also seen in some cases more than a year post-initial transplant (Chen et al., 2003). To understand how alterations following transplantation enhance susceptibility of HSCT patients to bacterial infections, we exposed syngeneic BMT mice to a sublethal dose of $P$. aeruginosa (PAO1 strain; $5 \times 10^{5}$ CFU) (Ojielo et al., 2003; Ballinger et al., 2006a, 2008; Coomes et al., 2011) or S. aureus (USA300 stain; $7 \times 10^{7} \mathrm{CFU}$ ) via intratracheal (i.t.) injection. Twenty-four hours post-infection, lungs and blood are collected to determine bacterial burden. Using this model, we found that syngeneic BMT mice are more susceptible to bacterial infections as they are unable to effectively clear P. aeruginosa (Ojielo et al., 2003; Ballinger et al., 2006a, 2008; Coomes et al., 2011; Domingo-Gonzalez et al., 2013) or S. aureus (Domingo-Gonzalez et al., 2013) from the lung and contain higher levels of bacterial dissemination compared to untransplanted, infected control mice. The remainder of this review will highlight the pathologic abnormalities which we have characterized in the innate immune cells using this model system. It should be noted that we utilized mice at week 5 post-BMT when hematopoietic reconstitution (including AMs) from donor HSCs was maximal (Hubbard et al., 2008). We assessed bacterial clearance $24 \mathrm{~h}$ postinfection and we used specific pathogen free mice; thus, there was little chance of co-infection. Using this model system, we have identified numerous BMT-induced changes that characterize the AMs and polymorphonuclear leukocytes (PMNs) that repopulate the host.

\section{CYTOKINE AND EICOSANOID DYSREGULATION POST-BMT}

In humans, bacterial infection is commonly seen in the neutropenic phase due to a slow or incomplete engraftment, or the use of immunosuppressive therapy (Afessa and Peters, 2006; Coomes et al., 2011). However, in our syngeneic BMT model, there was prolonged susceptibility to bacterial infection even after full hematopoietic engraftment had occurred. These observations suggested that the environment of the lung post-BMT may be suppressing the function of the innate immune cells which had repopulated the alveolar space. These studies revealed that syngeneic BMT mice are unable to successfully induce TNF $\alpha$ or IFN $\gamma$ in the lung following infection with $P$. aeruginosa (Ojielo et al., 2003). TNF $\alpha$ in particular, has been shown to be especially important in controlling a $P$. aeruginosa infection (Sapru et al., 1999; Chen et al., 2000). Balb/c mice are naturally resistant to $P$. aeruginosa and have been shown to produce higher levels of TNF $\alpha$ in the lung following infection while the susceptible C57Bl/6 strain produces significantly lower levels of TNF $\alpha$ post-infection (Gosselin, 1995; Morissette et al., 1995). Interestingly, in vivo treatment of Balb/c mice with an anti-murine TNF $\alpha$ monoclonal antibody reversed resistance to infection and the anti-TNF $\alpha$-treated mice exhibited higher bacterial loads in the lung (Gosselin, 1995). Similarly, a separate study showed that TNF $\alpha$-knockout mice suffered from significantly higher bacterial burden in the lungs following challenge with $P$. aeruginosa compared to their TNF $\alpha$-sufficient wild-type controls (Yu, 2000). These data highlight the importance of TNF $\alpha$ in mediating clearance of $P$. aeruginos $a$ and suggest that loss of the mediator post-BMT likely contributes to impaired clearance of this pathogen.

In addition to TNF $\alpha$, IFN $\gamma$ is also important for the activation of macrophages. IFN $\gamma$ functions to prime macrophages to undergo classical activation but does not alone activate macrophages (Nathan, 1991; Mosser, 2003). It requires a second signal, provided by either exogenous TNF $\alpha$ or Toll-like receptor (TLR)-induced TNF $\alpha$ (57). However, as both IFN $\gamma$ and TNF $\alpha$ were decreased in the alveolar space and TNF $\alpha$ production was decreased by AMs following BMT in response to i.t. challenge with $P$. aeruginosa, it is possible that the lack of activation signals for macrophages contribute to the inability to control and clear bacterial insult (Ojielo et al., 2003). 
Eicosanoids derive from arachidonic acid and are lipid mediators produced by different cell types, including alveolar epithelial cells (AECs), AMs, and PMNs (Ballinger et al., 2006a, 2007; Folco and Murphy, 2006). Prostaglandins and leukotrienes are end-products of arachidonic acid metabolism via the cyclooxygenase (COX) and 5-lipoxygenase enzymatic pathways, respectively (Folco and Murphy, 2006). These eicosanoids have diverse effects on cells. Leukotrienes ( $\mathrm{LTB}_{4}$ and cysteinyl leukotrienes or cys LTs) seem to have an overall pro-inflammatory effect on innate immune cells as they have been shown to promote bacterial phagocytosis and killing in both AMs and PMNs (Bailie, 1996; Mancuso et al., 1998; Mancuso, 2001; Serezani et al., 2005). Similarly, cys LTs have been shown to be involved in the induction of $\mathrm{TNF} \alpha$ production by both AMs and recruited PMNs (Sayers, 1988; Ménard, 2000). Studies on the effects of prostaglandins, particularly prostaglandin $\mathrm{E}_{2}\left(\mathrm{PGE}_{2}\right)$, however, suggest they may negatively regulate innate immune responses (Aronoff et al., 2004). PGE 2 signals through four distinct $G$ protein-coupled seven transmembrane spanning E prostanoid (EP) receptors (Funk, 2001; Hubbard et al., 2001). The inhibitory effects of $\mathrm{PGE}_{2}$ have been attributed to binding of EP2 and EP4. Stimulation of the EP2 or EP4 receptors results in the induction of intracellular cyclic adenosine monophosphate (cAMP) and activation of the downstream cAMP targets: protein kinase $\mathrm{A}$ (PKA) and the exchange protein activated by CAMP (Epac-1) (Aronoff et al., 2004, 2005). Activation of PKA and/or Epac-1 has been shown to impair both AM and PMN function as well as inhibit the production of pro-inflammatory mediators, leukotrienes, and reactive oxygen species (He, 2001; Aronoff et al., 2005). Interestingly, $\mathrm{PGE}_{2}$ has also been shown to induce IL-10, an immunosuppressive cytokine (Harizi, 2002; MacKenzie et al., 2012).

Prostaglandin $\mathrm{E}_{2}$ has been reported to be elevated in the serum of autologous HSCT recipients (Cayeux et al., 1993). This increase in $\mathrm{PGE}_{2}$ was not specific to a particular conditioning regimen indicating that all HSCT patients are susceptible to overproduction of $\mathrm{PGE}_{2}$ (Cayeux et al., 1993). We have previously reported that $\mathrm{PGE}_{2}$ is elevated in the lungs of mice following syngenic BMT (Ballinger et al., 2006a). This overproduction was localized to AMs, recruited PMNs, and structural cells, whereas cys LTs are decreased in BMT AMs (Ballinger et al., 2006a). The increased production of $\mathrm{PGE}_{2}$ is likely to be systemic as BMT peritoneal lavage fluid also displayed higher $\mathrm{PGE}_{2}$ levels (Ballinger et al., 2006a). Although it is tempting to suspect $\mathrm{PGE}_{2}$-induced IL-10 expression may be responsible for the impaired immune environment post-BMT, IL10 was decreased in the BMT lung following infectious stimuli indicating that the inhibitory effects of $\mathrm{PGE}_{2}$ were likely independent of the immunosuppressive effects of IL-10 (Ojielo et al., 2003). Interestingly, pharmacological inhibition of the COX pathway post-BMT limited $\mathrm{PGE}_{2}$ production and restored cysLT levels in AMs indicating that $\mathrm{PGE}_{2}$ negatively regulates cysLTs in the setting of BMT (Ballinger et al., 2006a). The importance of cysLTs in supporting the clearance and resolution of pulmonary infections post-BMT is observed in mice that received HSCs from granulocyte macrophage colony stimulating factor $(\mathrm{GM}-\mathrm{CSF})^{-/-}$mice (Ballinger et al., 2008). GM-CSF ${ }^{-/-}$BMT mice are defective in cysLT production post-infection and are more susceptible to $P$. aeruginosa infection.
Granulocyte macrophage colony stimulating factor is an important cytokine for regulating innate immune cells, particularly macrophages. Previous studies have shown that GMCSF is required for effective clearance of $P$. aeruginosa even in untransplanted mice (Ballinger et al., 2006b). Untransplanted

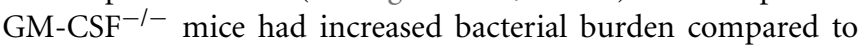
wild-type controls. However, the source and amount of GM-CSF is critical to determining host defense function post-BMT. AMs from wild-type syngeneic BMT mice show an overproduction of GM-CSF post-BMT. Interestingly, in human HSCT literature, elevated production of GM-CSF by AMs during the pancytopenia period was also noted (Whittle et al., 2001). While we initially thought excess AM-derived GM-CSF would be beneficial, this was not the case because the excess GM-CSF in AMs post-BMT drove upregulation of the EP2 receptor on AMs (Ballinger et al., 2008). The inhibitory effects of $\mathrm{PGE}_{2}$ signaling via upregulated EP2 in the wild-type BMT mice impaired bacterial phagocytosis and killing as well as cys LT and TNF $\alpha$ production. When GM-CSF ${ }^{-1-}$ HSCs were used to repopulate WT mice, host defense improved (Ballinger et al., 2008). Without AM-derived GM-CSF post-BMT, $\mathrm{EP} 2$ receptors were not elevated and mice showed improved host defense despite the fact that $\mathrm{PGE}_{2}$ levels were still elevated postBMT. In the absence of EP2 elevations, the $\mathrm{GM}^{-\mathrm{CSF}^{-1-} \mathrm{BMT}}$ mice retained production of cys LTs and TNF $\alpha$. It is important to stress that improved host defense was only seen in the situation where GM-CSF production was blocked in hematopoietic cells post-transplant. When WT HSCs were transplanted into GM$\mathrm{CSF}^{-1-}$ mice, host defense was once again impaired (Ballinger et al., 2008). These data highlight the importance of cross-talk between AECs and AMs post-BMT. AEC-derived GM-CSF is beneficial post-BMT whereas AM-derived GM-CSF is detrimental. In the human HSCT literature mentioned above, elevations of AM-derived GM-CSF in human allogenic HSCT recipients predicted development of later lung disease (Whittle et al., 2001). This complex homeostatic regulation of GM-CSF means blocking this cytokine needs to be targeted specifically to the AMs to be beneficial. Newer approaches to create microparticle delivery vesicles that are readily uptaken by phagocytes, but not structural cells may offer a way to deliver Ab or siRNA-based anti-GM-CSF therapies in the future (Jhunjhunwala and Little, 2011).

\section{CELLULAR ALTERATIONS}

\section{Alveolar macrophages}

Induction of $\mathrm{PGE}_{2}$ via cyclooxygenase-2 demethylation. Alveolar macrophages compose $95 \%$ of all leukocytes in the airspaces and thus, are the sentinel phagocytic cells in the lungs (Gordon and Read, 2002; Martin and Frevert, 2005). They have been implicated as critical innate immune cells for clearance of bacteria as depletion of AMs through clodronate liposomes resulted in impaired host defense against $P$. aeruginosa (Kooguchi et al., 1998). As AMs are key players in a productive innate immune response in the lungs, their function following transplantation is essential. However, data suggest that BMT AMs demonstrate altered cytokine and eicosanoid production which impair their innate immune function and predispose the host to infections post-BMT.

Prostaglandin $\mathrm{E}_{2}$ is significantly overproduced by BMT AMs (Ballinger et al., 2006a). The cause for elevated basal levels of $\mathrm{PGE}_{2}$ 
in the AMs post-BMT may be multifactorial. It is possible that differences in differentiation of AMs from donor-derived HSCs versus a resident $A M$ stem cell may influence the amount of $\mathrm{PGE}_{2}$ observed after transplant (Tarling et al., 1987). However, studies indicate that this cannot fully explain the defect since mice receiving a lower dose of irradiation (8 Gy) contain a large percentage of host-derived AMs $(\sim 36 \%)$ that also overproduce $\mathrm{PGE}_{2}$ posttransplant, albeit at approximately a threefold lower level than seen in AMs derived from donor HSCs (Hubbard et al., 2008). To further understand how $\mathrm{PGE}_{2}$ might be overproduced post-BMT, upstream regulators of $\mathrm{PGE}_{2}$ in the arachidonic acid metabolism cascade were analyzed. COX-2, the inducible form of COX, processes arachidonic acid to present to prostaglandin synthase enzymes to form prostaglandins (Funk, 2001). COX-2 expression is also increased following BMT (Domingo-Gonzalez, 2012). This increase in expression was due to significant hypomethylation of the COX-2 gene post-transplant. This demethylation induced expression of COX-2 and thus allowed increased $\mathrm{PGE}_{2}$ synthesis in the setting of BMT. The demethylation of the COX-2 gene was shown to be regulated at least in part via the actions of transforming growth factor beta (TGF $\beta$ ), another cytokine that is elevated in the lungs post-BMT and is produced by the AECs (Domingo-Gonzalez, 2012). To determine the effects of TGF $\beta$ on COX-2 expression in BMT AMs, mice containing a dominant negative TGF $\beta$ RII expressed under the CD11c promoter were used as donor mice (Domingo-Gonzalez, 2012). Thus, in these transplants, AMs would be insensitive to TGF $\beta$ signaling. These studies revealed that blocking TGF $\beta$ signaling restored methylation patterns within the COX-2 gene. Taken together, these studies indicate that elevations of TGF $\beta$ post-BMT induce COX-2 expression via demethylation of the gene (Domingo-Gonzalez, 2012). While not the subject of this review, it is interesting to note that elevations of TGF $\beta$ post-BMT also impair effector T cell responses and this alteration increases the susceptibility of BMT mice to herpesviral infections as well (Coomes et al., 2010, 2011).

Alveolar macrophages have been reported to exhibit decreased ability to phagocytose and kill bacteria following allogeneic HSCT (Winston et al., 1982). As AMs are important first responders to infection in the lung, their function is essential for preventing bacterial dissemination as well as promoting bacterial clearance by engulfment and removal of infectious pathogens, and also by releasing chemokines to stimulate the recruitment and activation of immune cells (Martin and Frevert, 2005). Murine BMT AMs display an impaired ability to phagocytose and kill $P$. aeruginosa (Ojielo et al., 2003; Ballinger et al., 2006a; Hubbard et al., 2010, 2011). This defect has been shown to be dependent on $\mathrm{PGE}_{2}$ signaling as pharmacological inhibition of the COX pathway through the use of indomethacin can restore a productive host defense against bacteria both in vitro and in vivo post-BMT. Furthermore, blocking the EP2 receptor (using AH 6809 a strong EP2 antagonist with weaker activity at the EP1 and DP1 receptors) in BMT AMs inhibits $\mathrm{PGE}_{2}$ signaling and restores phagocytosis of $P$. aeruginosa (Ballinger et al., 2006a). Thus, the next experiments discussed were undertaken to determine how $\mathrm{PGE}_{2}$ signaling inhibits $\mathrm{AM}$ phagocytosis and bacterial killing post-BMT.

Phosphatase and tensin homolog deleted on chromosome 10 (PTEN) elevations. Endocytosis of pathogens can occur in a number of ways with two major ways being through opsonized and non-opsonized phagocytosis. As bacterial uptake is impaired postBMT, we sought to better understand the reasons for this. PTEN functions to dephosphorylate both protein and lipid targets, and has been traditionally known for its effects on PI3K/AKT signaling through dephosphorylation of phosphatidylinositol (Cutler, 2005; Copelan, 2006; Passweg, 2012)-triphosphate (PIP 3 ) (Gunzl and Schabbauer, 2008). Previous studies have shown that $\mathrm{PGE}_{2}$ induced PTEN activity can inhibit Fc $\gamma$ R-mediated phagocytosis and PI3K/AKT activation (Canetti et al., 2007). In the syngeneic BMT model, overproduction of $\mathrm{PGE}_{2}$ stimulates increased PTEN activity, resulting in decreased serum-opsonized phagocytosis (Hubbard et al., 2011). Using myeloid-specific PTEN conditional knockout (PTEN CKO) mice as BMT donors, recipient mice had improved, but not completely restored, host defense to in vivo bacterial challenge. This rescued response correlated with recovered serum-opsonized phagocytosis by AMs and improved killing of $P$. aeruginosa by both AMs and PMNs. Interestingly, non-opsonized phagocytosis in AMs was only partially recovered (Hubbard et al., 2011). This partial restoration may be due to persisted elevation of the IL-1 receptor-associated kinase-M (IRAK-M) post-BMT.

IRAK-M elevations. A member of the IRAK family of serine/threonine kinases, IRAK-M functions as a negative regulator of MyD88-dependent TLR signaling (Kobayashi, 2002). Our BMT model revealed that $\mathrm{PGE}_{2}$ can upregulate IRAK-M in AMs (Hubbard et al., 2010). Furthermore, BMT mice receiving genetically ablated IRAK-M ${ }^{-1-}$ donor HSCs were able to control and clear the bacterial infection similarly to untransplanted controls. This recovery also correlated with rescued TNF $\alpha$, cys LTs, and AM function (including non-opsonized phagocytosis and killing) (Hubbard et al., 2010). Interestingly, these mice retained overproduction of $\mathrm{PGE}_{2}$ and overexpression of the inhibitory receptor, EP2. Thus, these data suggest that the inhibitory effects of $\mathrm{PGE}_{2}$ are dependent on IRAK-M and that IRAK-M is a critical downstream mediator of inhibitory $\mathrm{PGE}_{2}$ signaling (Hubbard et al., 2010). Taken together, these studies suggest that $\mathrm{PGE}_{2}$ signals through IRAK-M independently of PTEN and increased activity of IRAK-M and PTEN promote differential effects on opsonized and non-opsonized phagocytosis. Furthermore, the PTEN CKO studies highlight the importance of non-opsonized phagocytic responses in the lung following transplant, as complete recovery of serum-opsonized phagocytosis and bacterial killing did not completely abrogate in vivo susceptibility measured $24 \mathrm{~h}$ post-infection (Hubbard et al., 2011).

Scavenger receptor alterations. Non-opsonized phagocytosis is primarily mediated by scavenger receptors (SRs), specifically Class A SRs (Palecanda and Kobzik, 2001). Within this family of SRs are SR-AI and II, macrophage receptor with a collagenous structure (MARCO), SR with C-type lectin (SRCL), and SR receptor A5 (SCARA5) (Peiser et al., 2002). SR-AI and II are splice variants, and together with MARCO, have been associated with mediating non-opsonized phagocytosis in macrophages (Peiser et al., 2002). Their importance in bacterial clearance is highlighted by the susceptibility of individual $\mathrm{MARCO}^{-/-}$and SR-AI/II ${ }^{-1-}$ mice to S. pneumoniae (Arredouani et al., 2004, 2006). Defective phagocytosis of $S$. pneumoniae in $\mathrm{SR}-\mathrm{AI} / \mathrm{II}^{-1-}$ mice has also 
been reported (Arredouani et al., 2006). Interestingly, the impaired phagocytosis of non-opsonized $P$. aeruginosa in our BMT model correlated with aberrant SR profiles (decreased MARCO and increased SR-AI/II expression) (Domingo-Gonzalez et al., 2013). Treatment of untransplanted AMs with soluble MARCO, inhibited phagocytosis similarly to pan class A SR inhibitors and was comparable to the level of phagocytosis noted against $P$. aeruginosa in wild-type BMT AMs. In contrast, SR-AI/II overexpression explained the surprising enhancement of $S$. aureus phagocytosis by BMT AMs (Domingo-Gonzalez et al., 2013).

The differences in SR profiles observed following transplant can be attributed to $\mathrm{PGE}_{2}$. Exogenous treatment of naïve AMs with $\mathrm{PGE}_{2}$ decreased MARCO and increased SR-AI/II considerably (Domingo-Gonzalez et al., 2013). The mechanism(s) explaining how $\mathrm{PGE}_{2}$ is able to regulate SR expression is not fully characterized. However, our studies revealed that $\mathrm{PGE}_{2}$ can inhibit expression of microRNA-155 (miR-155) (Domingo-Gonzalez et al., 2013). MicroRNAs are small non-coding RNAs that typically target $3^{\prime}$ untranslated regions ( $3^{\prime}$ UTR) and can inhibit or stabilize mRNA expression or in many cases inhibit mRNA translation (He and Hannon, 2004; Chen and Rajewsky, 2007). miR-155 has been generally shown to play a role in promoting an inflammatory response as it has been shown to stabilize TNF $\alpha$ mRNA and thus promote expression (Bala et al., 1436). In the context of transplant, miR-155 expression is decreased by $\mathrm{PGE}_{2}$ (Domingo-Gonzalez et al., 2013). Interestingly, the $3^{\prime} \mathrm{UTR}$ of SR-AI/II contains a putative miR-155 target sequence (TargetScan). Blocking miR-155 can induce expression of SR-AI/II and result in enhanced phagocytosis of S. aureus (Domingo-Gonzalez et al., 2013). These results suggest that by negatively regulating an inhibitor of SR-AI/II, $\mathrm{PGE}_{2}$ can indirectly induce expression of this SR. The mechanism for how $\mathrm{PGE}_{2}$ reduces MARCO expression is unknown at present, but does not involve miR-155. Importantly, despite differences in levels of phagocytosis of $P$. aeruginosa and $S$. aureus, a defect in killing remains in BMT AMs which ultimately confers susceptibility to both bacterial infections (Domingo-Gonzalez et al., 2013). As mentioned above, this killing defect may relate to both IRAK-M elevation and PTEN activation post-BMT. Loss of miR155 in response to $\mathrm{PGE}_{2}$ signaling may also serve to destabilize TNF $\alpha$ mRNA post-BMT, and this is also likely to impair bacterial killing.

\section{Lung epithelial cells}

Alveolar epithelial cells are the structural cells lining the alveolus. Type II AECs are important secretors of pulmonary surfactant, are progenitors to type I AECs which line the majority of the lung, and act as immunomodulators via interactions with immune cells. Exposure to ionizing radiation induces damage to the alveolar epithelial barrier causing changes in gene expression, particularly cytokine expression (Rubin et al., 1995). We have previously shown that upon transplantation, AECs from BMT mice are negatively affected by the transplant process. Specifically, AECs overproduce $\mathrm{PGE}_{2}$ as well as TGF $\beta$ which as discussed above inhibits AM function (Ballinger et al., 2006a; Coomes et al., 2010; Domingo-Gonzalez, 2012). Furthermore, AECs are defective in the synthesis of GM-CSF (Ballinger et al., 2006b, 2008) which as discussed above is important for modulating AM function.
Another important defect that has been described post-BMT is the loss of surfactant protein A (SPA) which is predominantly synthesized by AECs (Yang, 2000; Wright, 2005). As SPA can serve as a collectin (Wright, 2005) which can bind pathogens to help facilitate phagocytosis via the SR-AI/II receptor (Kuronuma, 2004), loss of SPA post-BMT may be another reason why host defense is impaired in the setting of HSCT. The fact that SPA can bind to SR-AI/II (the receptor that is retained on BMT AMs) may suggest that exogenous SPA therapy could prove beneficial post-HSCT.

\section{Polymorphonuclear leukocytes}

A major role for PMNs lies in their ability to be recruited to the lung upon inflammation or infection and assist in the killing and ultimate clearance of pathogens (Wang, 2004; Koh, 2009). Several studies have looked at the function of human PMNs post-autologous HSCT (reviewed in Ramaprasad et al., 2010). These human studies noted decreased respiratory burst, decreased phagocytosis of $C$. albicans and decreased killing of $S$. aureus (Gadish et al., 1991). Interestingly the role of GM-CSF in restoring PMN function is mixed (Peters et al., 1988; Gadish et al., 1991; Wiltschke et al., 1995).

In the context of murine syngeneic BMT, PMNs were shown to have intact phagocytic ability but were defective in their ability to kill the engulfed bacteria (Ballinger et al., 2006a). Genetic ablation of GM-CSF in donor marrow improved, but did not fully restore, PMN killing of P. aeruginosa (Ballinger et al., 2008).

PTEN-deficient neutrophils have been reported to exhibit enhanced host immune responses (Subramanian et al., 2007; Li et al., 2009). Previous studies had shown that alleviating the repressive effect of PTEN on neutrophils, augmented neutrophil chemotaxis (Subramanian et al., 2007). Similar to these studies, our PTEN CKO BMT mice had elevated basal levels of PMNs in the alveolar space compared to untransplanted wild-type controls and recovered their ability to kill intracellular bacteria (Hubbard et al., 2011). However, despite a rescued PMN phenotype, PTEN CKO BMT mice were still susceptible to acute $P$. aeruginosa infection, highlighting the importance AM function, specifically the need for non-opsonized phagocytosis, post-BMT.

Table 1 | Summary of observed cellular alterations following syn-BMT.

\begin{tabular}{lll}
\hline AECs AMs PMNs \\
\hline
\end{tabular}

Cytokines (baseline $\uparrow T G F \beta, P G E_{2}, \quad$ GM-CSF, PGE $2, \quad \uparrow P G E_{2}$ and post-infection) $\quad \downarrow$ GM-CSF $\quad \downarrow$ CysLTs, TNF $\alpha$

Function

$\downarrow$ Phagocytosis, $\quad \downarrow$ Bacterial killing bacterial killing

Intracellular

个PTEN, IRAK-M LOSS Of PTEN

signaling

improves function, IRAK-M levels do not change

miRNA $\downarrow$ miR-155

Scavenger $\uparrow S R-A I / I I$, receptors 


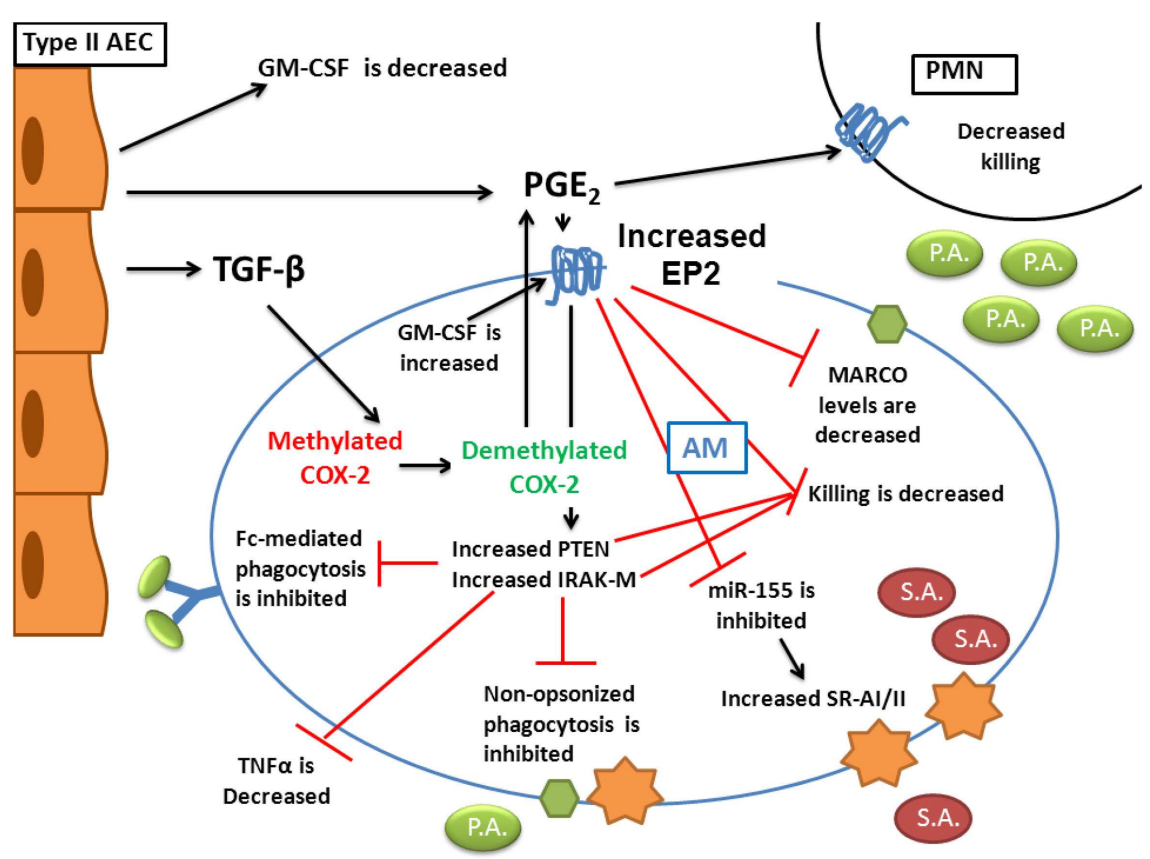

FIGURE 1 | Alterations in innate immunity post-BMT. AEC production of TGF $\beta$ and $P G E_{2}$ are increased following transplant and both affect $A M$ function. AEC production of GM-CSF is reduced. TGF $\beta$ signaling in AMs helps demethylate the COX-2 promoter to increase AM-derived $\mathrm{PGE}_{2}$ secretion. Overproduction of GM-CSF in AMs post-BMT leads to elevation of the EP2 receptor. In response to $\mathrm{PGE}_{2}$ stimulation of increased $\mathrm{EP} 2$ receptors, AM phagocytosis of both opsonized and unopsonized pathogens is impaired. This impaired phagocytosis is related to a loss of
MARCO expression as well as an upregulation of IRAK-M. Despite the fact that $\mathrm{PGE}_{2}$ reduces miR-155 which leads to increased SR-AI/II expression, bacterial killing in both AMs and PMNs is impaired. This is related to activation of PTEN as well as increased IRAK-M. Not shown on the diagram is the observation that TNF $\alpha$ expression in AMs is also lost as a result of $\mathrm{PGE}_{2}$ signaling. We have demonstrated that these alterations ultimately lead to impaired host defense against both Gram-negative $P$. aeruginosa as well as Gram-positive $S$. aureus.
Together with AMs, the impaired function of PMNs can also be attributed to elevated $\mathrm{PGE}_{2}$, as pharmacological inhibition of $\mathrm{PGE}_{2}$ synthesis completely resolved their defect (Ballinger et al., 2006a). Unlike BMT AMs, PMNs do not exhibit a phagocytic defect and IRAK-M is not elevated in recruited PMNs. Thus, it is likely that $\mathrm{PGE}_{2}$ is mediating impaired killing through PTEN, as we have previously shown that $\mathrm{PGE}_{2}$ can induce PTEN activity (Hubbard et al., 2011).

\section{CONCLUSION}

The cumulative data from our studies of murine syngeneic BMT is summarized in Table $\mathbf{1}$ and suggests that the susceptibility to pulmonary infections following HSCT is related to the prolonged impairment of immune function, particularly of AMs and PMNs, as well as cytokine alterations by AECs. The master innate immune inhibitory mediator post-BMT appears to be $\mathrm{PGE}_{2}$. Defects of AM phagocytosis and killing as well as defects in PMN killing limit the ability of the host to fight off bacterial infections post-HSCT. Blockade of $\mathrm{PGE}_{2}$ signaling or production can restore innate immune function. Work using this BMT mouse model provides critical insight into the causes of defective pulmonary immunity observed in the setting of transplantation and in the absence of immunosuppressive therapy or the confounding effects of GvHD.

Changes that characterize BMT AMs are diverse. Figure 1 provides a schematic overview of the changes that occur in AMs following transplant. It is interesting that most of the changes that occur can be attributed to eicosanoid dysregulation and the enhanced signaling of $\mathrm{PGE}_{2}$ through overexpression of one of its receptors, EP2. Signaling via EP2 regulates downstream targets; IRAK-M is increased and PTEN is activated post-BMT. The end result of these alterations is the impairment of AM and PMN function. The use of general COX inhibitors (e.g., indomethacin or aspirin) or COX-2-specific inhibitors (e.g., NS-398) may prove beneficial to HSCT patients. More recently, the development of PF044148948, the first specific EP2 antagonist developed by Pfizer (Wang, 2004) may offer the exciting advantage of blocking the inhibitory effects of $\mathrm{PGE}_{2}$ signaling on AMs without shutting down all prostaglandin production or effecting other EP receptor signaling. Such a therapeutic may offer protection to HSCT patients suffering from antibiotic resistant bacterial infections. Finally, murine studies need to be confirmed in human HSCT AMs. If elevations in COX-2 and EP2 signaling as well as loss of SPA noted in murine studies can be verified in humans postHSCT, the next step will be to design clinical trials to test therapies targeted at these transplant-induced alterations.

\section{ACKNOWLEDGMENTS}

This work was supported by NIH grants R56AI065543 and T32AI007413, and a predoctoral fellowship from the American Heart Association. 


\section{REFERENCES}

Afessa, B. (2001). Bronchiolitis obliterans and other late onset non-infectious pulmonary complications in hematopoietic stem cell transplantation. Bone Marrow Transplant. 28, 425-434. doi:10.1038/sj.bmt.1703142

Afessa, B., Abdulai, R. M., Kremers, W. K., Hogan, W. J., Litzow, M. R., and Peters, S. G. (2012). Risk factors and outcome of pulmonary complications after autologous hematopoietic stem cell transplanthematopoietic stem cell transplant complications. Chest 141, 442-450. doi:10.1378/chest. 10-2889

Afessa, B., and Peters, S. G. (2006). Major complications following hematopoietic stem cell transplantation. Semin. Respir. Crit. Care Med. 27, 297-309. doi:10.1055/s-2006-945530

Aronoff, D. M., Canetti, C., and PetersGolden, M. (2004). Prostaglandin E2 inhibits alveolar macrophage phagocytosis through an E-prostanoid 2 receptor-mediated increase in intracellular cyclic AMP. J. Immunol. 173, 559-565.

Aronoff, D. M., Canetti, C., Serezani, C. H., Luo, M., and Peters-Golden, M. (2005). Cutting edge: macrophage inhibition by cyclic AMP (cAMP): differential roles of protein kinase A and exchange protein directly activated by cAMP-1. J. Immunol. 174, 595-599.

Arredouani, M., Yang, Z., Ning, Y., Qin, G., Soininen, R., Tryggvason, K., et al. (2004). The scavenger receptor MARCO is required for lung defense against pneumococcal pneumonia and inhaled particles. J. Exp. Med. 200, 267-272. doi:10.1084/jem.20040731

Arredouani, M. S., Yang, Z., Imrich, A., Ning, Y., Qin, G., and Kobzik, L. (2006). The macrophage scavenger receptor SR-AI/II and lung defense against pneumococci and particles. Am. J. Respir. Cell Mol. Biol. 35, 474-478. doi:10.1165/rcmb.2006-0128OC

Asano-Mori, Y. (2010). Fungal infections after hematopoietic stem cell transplantation. Int. J. Hematol. 91, 576-587. doi:10.1007/s12185010-0574-0

Aschan, J. (2007). Risk assessment in haematopoietic stem cell transplantation: conditioning. Best Pract. Res. Clin. Haematol. 20, 295-310. doi:10.1016/j.beha.2006.09.004

Bailie, M. B. (1996). Leukotrienedeficient mice manifest enhanced lethality from Klebsiella pneumonia in association with decreased alveolar macrophage phagocytic and bactericidal activities. J. Immunol. 157, 5221-5224.

Bala, S., Marcos, M., Kodys, K., Csak, T., Catalano, D., Mandrekar, P., et al. (1436). Up-regulation of microRNA155 in macrophages contributes to increased tumor necrosis factor $\{$ alpha $\}$ (TNF $\{$ alpha $\}$ ) production via increased mRNA half-life in alcoholic liver disease. J. Biol. Chem. 286, 1436-1444. doi:10.1074/jbc.M110.145870

Ballinger, M. N., Aronoff, D. M., McMillan, T. R., Cooke, K. R., Okiewicz, K., Toews, G. B., et al. (2006a). Critical role of prostaglandin E2 overproduction in impaired pulmonary host response following bone marrow transplantation. J. Immunol. 177, 5499-5508.

Ballinger, M. N., Paine, R. III, Serezani, C. H., Aronoff, D. M., Choi, E. S., Standiford, T. J., et al. (2006b). Role of granulocyte macrophage colony-stimulating factor during gram-negative lung infection with Pseudomonas aeruginosa. Am. J. Respir. Cell Mol. Biol. 34, 766-774. doi:10.1165/rcmb.2005-0246OC

Ballinger, M. N., Hubbard, L. L., McMillan, T. R., Toews, G. B., Peters-Golden, M., Paine, R. III, et al. (2008). Paradoxical role of alveolar macrophage-derived granulocyte-macrophage colonystimulating factor in pulmonary host defense post-bone marrow transplantation. Am. J. Physiol. Lung Cell Mol. Physiol. 295, L114-L122. doi:10.1152/ajplung.00309.2007

Ballinger, M. N., McMillan, T. R., and Moore, B. B. (2007). Eicosanoid regulation of pulmonary innate immunity post-hematopoietic stem cell transplantation. Arch. Immunol. Ther. Exp. (Warsz.) 55, 1-12. doi:10.1007/s00005-007-0001-2

Boeckh, M. (2003). Cytomegalovirus in hematopoietic stem cell transplant recipients: current status, known challenges, and future strategies. Biol. Blood Marrow Transplant. 9, 543-558. doi:10.1016/S10838791(03)00287-8

Boeckh, M. (2011). Complications, diagnosis, management, and prevention of CMV infections: current and future. Hematology Am. Soc. Hematol. Educ. Program 2011, 305-309. doi:10.1182/asheducation-

2011.1.305

Bow, E. J. (2009). Invasive fungal infection in haematopoietic stem cell transplant recipients: epidemiology from the transplant physician's viewpoint. Mycopathologia 168, 283-297. doi:10.1007/s11046-009-9196-6

Canetti, C., Serezani, C. H., Atrasz, R. G., White, E. S., Aronoff, D. M., and Peters-Golden, M. (2007). Activation of phosphatase and tensin homolog on chromosome 10 mediates the inhibition of FcgammaR phagocytosis by prostaglandin E2 in alveolar macrophages. J. Immunol. 179, 8350-8356.

Cayeux, S. J., Beverly, P. C. L., Schulz, R., and Dorken, B. (1993). Elevated plasma prostaglandin E2 levels found in 14 patients undergoing autologous or stem cell transplantation. Bone Marrow Transplant. 12, 603-608.

Chandrasekar, P. H. (1995). Autopsyidentified infections among bone marrow transplant recipients: a clinico-pathologic study of 56 patients. Bone Marrow Transplantation Team. Bone Marrow Transplant. 16, 675-681.

Chen, C.-S., Boeckh, M., Seidel, K., Clark, J. G., Kansu, E., Madtes, D. K., et al. (2003). Incidence, risk factors, and mortality from pneumonia developing late after hematopoietic stem cell transplantation. Bone Marrow Transplant. 32, 515-522. doi:10.1038/sj.bmt.1704162

Chen, G. H., Reddy, R. C., Newstead, M. W., Tateda, K., Kyasapura, B. L., and Standiford, T. J. (2000). Intrapulmonary TNF gene therapy reverses sepsis-induced suppression of lung antibacterial host defense. $J$. Immunol. 165, 6496-6503.

Chen, K., and Rajewsky, N. (2007). The evolution of gene regulation by transcription factors and microRNAs. Nat. Rev. Genet. 8, 93-103. doi:10.1038/nrg1990

Coomes, S. M., Hubbard, L. L., and Moore, B. B. (2011). Impaired pulmonary immunity post-bone marrow transplant. Immunol. Res. 50, 78-86. doi:10.1007/s12026-0108200-z

Coomes, S. M., Wilke, C. A., Moore, T. A., and Moore, B. B. (2010). Induction of TGF-beta 1, not regulatory $\mathrm{T}$ cells, impairs antiviral immunity in the lung following bone marrow transplant. J. Immunol. 184, 5130-5140. doi:10.4049/jimmunol.0901871

Copelan, E. A. (2006). Hematopoietic stem-cell transplantation. $N$. Engl. J. Med. 354, 1813-1826. doi:10.1056/NEJMra052638

Cordonnier, C. (1986). Pulmonary complications occurring after allogeneic bone marrow transplantation. A study of 130 consecutive transplanted patients. Cancer 58, 1047-1054. doi:10.1002/10970142(19860901)58:5<1047::AIDCNCR2820580512>3.0.CO;2-Y

Cruciani, M. (1996). Prophylaxis with fluoroquinolones for bacterial infections in neutropenic patients: a meta-analysis. Clin. Infect. Dis. 23, 795-805. doi:10.1093/clinids/23.4.795

Cutler, C. (2005). An overview of hematopoietic stem cell transplantation. Clin. Chest Med. 26, 517-527. doi:10.1016/j.ccm.2005.06.016

Domingo-Gonzalez, R. (2012). COX-2 expression is upregulated by DNA hypomethylation after hematopoietic stem cell transplantation. J. Immunol. 189, 4528-4536. doi:10.4049/jimmunol.1201116

Domingo-Gonzalez, R., Katz, S., Serezani, C., Moore, T., LeVine, A., and Moore, B. (2013). PGE 2 induced changes in alveolar macrophage scavenger receptor profiles differentially alter phagocytosis of $P$. aeruginosa and $S$. aureus post-bone marrow transplant. J. Immunol. doi:10.4049/jimmunol.1203274 (in press)

Folco, G., and Murphy, R. C. (2006). Eicosanoid transcellular biosynthesis: from cell-cell interactions to in vivo tissue responses. Pharmacol. Rev. 58, 375-388. doi:10.1124/pr.58.3.8

Funk, C. D. (2001). Prostaglandins and leukotrienes: advances in eicosanoid biology. Science 294, 1871-1875. doi:10.1126/science.294.5548.1871

Gadish, M., Kletter, Y., Flidel, O., Nagler, A., Slavin, S., and Fabian, I. (1991). Effects of recombinant human granulocyte and granulocyte-macrophage colonystimulating factors on neutrophil function following autologous bone marrow transplantation. Leuk. Res. 15, 1175-1182. doi:10.1016/0145-2126(91)90187-X

Giralt, S. (2005). Reduced-intensity conditioning regimens for hematologic malignancies: what have we learned over the last 10 years? Hematology Am. Soc. Hematol. Educ. Program 2005, 384-389. doi:10.1182/asheducation2005.1.384

Gordon, S. B., and Read, R. C. (2002). Macrophage defences against respiratory tract infections. Br. Med. Bull. 61, 45-61. doi:10.1093/bmb/61.1.45

Gosselin, D. (1995). Role of tumor necrosis factor alpha in innate resistance to mouse pulmonary infection with Pseudomonas aeruginosa. Infect. Immun. 63, 3272-3278. 
Gratwohl, A., Baldomero, H., Aljurf, M., Pasquini, M. C., Bouzas, L. F., Yoshimi, A., et al. (2010). Hematopoietic stem cell transplantation: a global perspective. JAMA 303, 1617-1624. doi:10.1001/jama.2010.491

Griese, M. (2000). Pulmonary complications after bone marrow transplantation in children: twentyfour years of experience in a single pediatric center. Pediatr. Pulmonol. 30, 393-401. doi:10.1002/10990496(200011)30:5<393::AIDPPUL5>3.0.CO;2-W

Gunzl, P., and Schabbauer, G. (2008). Recent advances in the genetic analysis of PTEN and PI3K innate immune properties. Immunobiology 213, 759-765. doi:10.1016/j.imbio.2008.07.028

Hakki, M., Limaye, A. P., Kim, H. W., Kirby, K. A., Corey, L., and Boeckh, M. (2007). Invasive Pseudomonas aeruginosa infections: high rate of recurrence and mortality after hematopoietic cell transplantation. Bone Marrow Transplant. 39, 687-693. doi:10.1038/sj.bmt.1705653

Harizi, H. (2002). Cyclooxygenase-2issued prostaglandin $\mathrm{e}(2)$ enhances the production of endogenous IL10 , which down-regulates dendritic cell functions. J. Immunol. 168, 2255-2263.

He, L., and Hannon, G. J. (2004). MicroRNAs: small RNAs with a big role in gene regulation. Nat. Rev. Genet. 5, 522-531. doi: $10.1038 / \operatorname{nrg} 1415$

He, L. K. (2001). The expression of cyclooxygenase and the production of prostaglandin E2 in neutrophils after burn injury and infection. J. Burn Care Rehabil. 22, 58-64. doi:10.1097/00004630200101000-00012

Hubbard, L., Wilke, C., White, E., and Moore, B. P. T. E. N. (2011). Limits alveolar macrophage function against Pseudomonas aeruginosa following bone marrow transplantation. Am. J. Respir. Cell Mol. Biol. 45, 1050-1058. doi:10.1165/rcmb.20110079OC

Hubbard, L. L., Ballinger, M. N., Thomas, P. E., Wilke, C. A., Standiford, T. J., Kobayashi, K. S., et al. (2010). A role for IL-1 receptor-associated kinase-M in prostaglandin E2induced immunosuppression post-bone marrow transplantation. J. Immunol. 184, 6299-6308. doi:10.4049/jimmunol.0902828

Hubbard, L. L., Ballinger, M. N., Wilke, C. A., and Moore, B. B.
(2008). Comparison of conditioning regimens for alveolar macrophage reconstitution and innate immune function post bone marrow transplant. Exp. Lung Res. 34, 263-275. doi:10.1080/01902140802022518

Hubbard, N. E., Lee, S., Lim, D., and Erickson, K. L. (2001). Differential mRNA expression of prostaglandin receptor subtypes in macrophage activation. Prostaglandins Leukot. Essent. Fatty Acids 65, 287-294. doi:10.1054/plef.2001.0327

Jhunjhunwala, S., and Little, S. R. (2011). Microparticulate systems for targeted drug delivery to phagocytes. Cell 10, 2047-2048.

Kato, K., Cui, S., Kuick, R., Mineishi, S., Hexner, E., Ferrara, J. L., et al. (2010). Identification of stem cell transcriptional programs normally expressed in embryonic and neural stem cells in alloreactive $\mathrm{CD} 8+\mathrm{T}$ cells mediating graftversus-host disease. Biol. Blood Marrow Transplant. 16, 751-771. doi:10.1016/j.bbmt.2010.01.012

Kim, S. H., Kee, S. Y., Lee, D. G., Choi, S. M., Park, S. H., Kwon, J. C., et al. (2013). Infectious complications following allogeneic stem cell transplantation: reduced-intensity vs. myeloablative conditioning regimens. Transpl. Infect. Dis. 15, 49-59. doi:10.1111/tid.12003

Kobayashi, K. (2002). IRAK-M is a negative regulator of Toll-like receptor signaling. Cell 110, 191-202. doi:10. 1016/S0092-8674(02)00827-9

Koh, A. Y. (2009). Inescapable need for neutrophils as mediators of cellular innate immunity to acute Pseudomonas aeruginosa pneumonia. Infect. Immun. 77, 5300-5310. doi:10.1128/IAI.00501-09

Kolb, H.-J. (2008). Graft-versusleukemia effects of transplantation and donor lymphocytes. Blood 112, 4371-4383. doi:10.1182/blood-2008-03-077974

Kooguchi, K., Hashimoto, S., Kobayashi, A., Kitamura, Y., Kudoh, I., WienerKronish, J., et al. (1998). Role of alveolar macrophages in initiation and regulation of inflammation in Pseudomonas aeruginosa pneumonia. Infect. Immun. 66, 3164-3169.

Körbling, M., and Anderlini, P. (2001). Peripheral blood stem cell versus bone marrow allotransplantation: does the source of hematopoietic stem cells matter? Blood 98, 2900-2908. doi:10.1182/blood.V98.10.2900

Kotloff, R., Ahya, V., and Crawford, S. W. (2004). Pulmonary complications of solid organ and hematopoietic stem cell transplantation. Am. J. Respir. Crit. Care Med. 170, 22-48. doi:10.1164/rccm.200309-1322SO

Kuronuma, K. (2004). Pulmonary surfactant protein A augments the phagocytosis of Streptococcus pneumoniae by alveolar macrophages through a casein kinase 2-dependent increase of cell surface localization of scavenger receptor A. J. Biol. Chem. 279, 21421-21430. doi:10.1074/jbc.M312490200

Li, Y., Jia, Y., Pichavant, M., Loison, F., Sarraj, B., Kasorn, A., et al. (2009). Targeted deletion of tumor suppressor PTEN augments neutrophil function and enhances host defense in neutropenia-associated pneumonia. Blood 113, 4930-4941. doi:10.1182/blood-2008-06-161414

Lim, D. H. (2006). Pulmonary complications after hematopoietic stem cell transplantation. $J$. Korean Med. Sci. 21, 406-411. doi:10.3346/jkms.2006.21.3.406

Little, M.-T., and Storb, R. (2002). History of haematopoietic stem-cell transplantation. Nat. Rev. Cancer 2 , 231-238. doi:10.1038/nrc748

Ljungman, P. (2002). Prevention and treatment of viral infections in stem cell transplant recipients. Br. J. Haematol. 118, 44-57. doi:10.1046/j.13652141.2002.03515.x

Lorenz, E. (1951). Modification of irradiation injury in mice and guinea pigs by bone marrow injections. J. Natl. Cancer Inst. 12, 197-201.

MacKenzie, K. F., Clark, K., Naqvi, S., McGuire, V. A., Nöehren, G., Kristariyanto, Y., et al. (2012). PGE2 induces macrophage IL-10 production and a regulatory-like phenotype via a protein kinase A-SIK-CRTC3 pathway. J. Immunol. 190, 565-577. doi:10.4049/jimmunol.1202462

Mancuso, P. (2001). Leukotriene B4 augments neutrophil phagocytosis of Klebsiella pneumoniae. Infect. Immun. 69, 2011-2016. doi:10.1128/IAI.69.4.20112016.2001

Mancuso, P., Standiford, T. J., Marshall, T., and Peters-Golden, M. (1998). 5-Lipoxygenase reaction products modulate alveolar macrophage phagocytosis of Klebsiella pneumoniae. Infect. Immun. 66, 5140-5146.

Marr, K., Carter, R., Boeckh, M., Martin, P., and Corey, L. (2002). Invasive aspergillosis in allogeneic stem cell transplant recipients: changes in epidemiology and risk factors. Blood 100, 4358-4366. doi:10.1182/blood2002-05-1496
Marr, K. A. (2012). Delayed opportunistic infections in hematopoietic stem cell transplantation patients: a surmountable challenge. Hematology Am. Soc. Hematol. Educ. Program 2012, 265-270. doi:10.1182/asheducation2012.1.265

Martin, T. R., and Frevert, C. W. (2005). Innate immunity in the lungs. Proc. Am. Thorac. Soc. 2, 403-411. doi:10.1513/pats.200508090JS

Ménard, G. (2000). Priming of alveolar macrophages by leukotriene $\mathrm{D}(4)$ : potentiation of inflammation. Am. J. Respir. Cell Mol. Biol. 23, 572-577. doi:10.1165/ajrcmb.23.4.4152

Metcalf, J. P., Rennard, S. I., Reed, E. C., Haire, W. D., Sisson, J. H., Walter, T., et al. (1994). Corticosteroids as adjunctive therapy for diffuse alveolar hemorrhage associated with bone marrow transplantation. Am. J. Med. 96, 327-334. doi:10.1016/0002-9343(94)90062-0

Morissette, C., Skamene, E., and Gervais, F. (1995). Endobronchial inflammation following Pseudomonas aeruginosa infection in resistant and susceptible strains of mice. Infect. Immun. 63, 1718-1724.

Mosser, D. M. (2003). The many faces of macrophage activation. J. Leukoc. Biol. 73, 209-212. doi:10.1189/jlb.0602325

Nathan, C. (1991). Mechanisms and modulation of macrophage activation. Behring Inst. Mitt. 88, 200-207.

Ojielo, C., Cooke, K. R., Mancuso, P., Standiford, T. J., Olkiewicz, K. M. Cloutheir, S., et al. (2003). Defective phagocytosis and clearance of Pseudomonas aeruginosa in the lung following bone marrow transplantation. J. Immunol. 171, 4416-4424.

Palecanda, A., and Kobzik, L. (2001). Receptors for unopsonized particles: the role of alveolar macrophage scavenger receptors. Curr. Mol. Med. 1, 589-595. doi:10.2174/1566524013363384

Passweg, J. R. (2012). Hematopoietic stem cell transplantation: a review and recommendations for followup care for the general practitioner. Swiss. Med. Wkly. 142, w13696. doi:10.4414/smw.2012.13696

Peffault de Latour, R., Rocha, V., and Socie, G. (2013). Cord blood transplantation in aplastic anemia. Bone Marrow Transplant. 48, 201-202. doi:10.1038/bmt.2012.252

Peiser, L., Mukhopadhyay, S., and Gordon, S. (2002). Scavenger receptors in innate immunity. Curr. Opin. Immunol. 14, 123-128. 
doi:10.1016/S0952-7915(01)00

307-7

Peters, W. P., Stuart, A., Affronti, M. L., Kim, C. S., and Coleman, R. E. (1988). Neutrophil migration is defective during recombinant human granulocyte-macrophage colony-stimulating factor infusion after autologous bone marrow transplantation in humans. Blood 72, 1310-1315.

Ramaprasad, C., Pouch, S., and Pitrak, D. L. (2010). Neutrophil function after bone marrow and hematopoietic stem cell transplant. Leuk. Lymphoma 51, 756-767. doi:10.3109/10428191003695678

Reddy, P., Maeda, Y., Liu, C., Krijanovski, O. I., Korngold, R., and Ferrara, J. L. (2005). A crucial role for antigenpresenting cells and alloantigen expression in graft-versus-leukemia responses. Nat. Med. 11, 1244-1249. doi:10.1038/nm1309

Roychowdhury, M. (2005). Pulmonary complications after bone marrow transplantation: an autopsy study from a large transplantation center. Arch. Pathol. Lab. Med. 129, 366-371.

Roziakova, L. (2011). Secondary malignancies after hematopoietic stem cell transplantation. Neoplasma 58, 1-8. doi:10.4149/neo_2011_01_1

Rubin, P., Johnston, C. J., Williams, J. P., McDonald, S., and Finkelstein, J. N. (1995). A perpetual cascade of cytokines postirradiation leads to pulmonary fibrosis. Int. J. Radiat. Oncol. Biol. Phys. 33, 99-109. doi:10.1016/0360-3016(95)00095-G

Sapru, K., Stotland, P. K., and Stevenson, M. M. (1999). Quantitative and qualitative differences in bronchoalveolar inflammatory cells in Pseudomonas aeruginosa-resistant and -susceptible mice. Clin. Exp. Immunol. 115, 103-109. doi:10.1046/j.13652249.1999.00762.x

Sayers, T. J. (1988). Effect of cytokines on polymorphonuclear neutrophil infiltration in the mouse. Prostaglandin- and leukotriene-independent induction of infiltration by IL-1 and tumor necrosis factor. J. Immunol. 141, 1670-1677.

Serezani, C. H., Aronoff, D. M., Jancar, S., Mancuso, P., and PetersGolden, M. (2005). Leukotrienes enhance the bactericidal activity of alveolar macrophages against Klebsiella pneumoniae through the activation of NADPH oxidase. Blood 106, 1067-1075. doi:10.1182/blood2004-08-3323

Soubani, A. O. (1996). Pulmonary complications of bone marrow transplantation. Chest 109, 1066-1077. doi:10.1378/chest.109.4.1066

Soubani, A. O., Miller, K. B., and Hassoun, P. M. (1996). Pulmonary complications of bone marrow transplantation. Chest 109, 1066-1077. doi:10.1378/chest.109.4.1066

Soubani, A. O., and Uberti, J. P. (2007). Bronchiolitis obliterans following haematopoietic stem cell transplantation. Eur. Respir. J. 29, 1007-1019. doi:10.1183/09031936.00052806

Subramanian, K. K., Jia, Y., Zhu, D., Simms, B. T., Jo, H., Hattori, H., et al. (2007). Tumor suppressor PTEN is a physiologic suppressor of chemoattractantmediated neutrophil functions. Blood 109, 4028-4037. doi:10.1182/blood-2006-10-055319

Tarling, J. D., Lin, H. S., and Hsu, S. (1987). Self-renewal of pulmonary alveolar macrophages: evidence from radiation chimera studies. J. Leukoc. Biol. 42, 443-446.

Therriault, B. L. (2010). Characterization of bacterial infections in allogeneic hematopoietic stem cell transplant recipients who received prophylactic levofloxacin with either penicillin or doxycycline. Mayo Clin. Proc. 85, 711-718. doi:10.4065/mcp.2010.0006

Tomita, Y. (1994). Myelosuppressive conditioning is required to achieve engraftment of pluripotent stem cells contained in moderate doses of syngeneic bone marrow. Blood 83 , 939-948.

Tse, W. (2008). New insights into cord blood stem cell transplantation. Curr. Opin. Hematol. 15, 279-284. doi:10.1097/MOH.0b013e328304ae2c

Versluys, A. B. (2010). Strong association between respiratory viral infection early after hematopoietic stem cell transplantation and the development of life-threatening acute and chronic alloimmune lung syndromes. Biol. Blood Marrow Transplant. 16, 782-791. doi:10.1016/j.bbmt.2009.12.534

Wang, Q. (2004). Neutrophils in innate immunity. Semin. Respir. Crit. Care Med. 25, 33-41. doi:10.1055/s-2004822303

Whittle, A. T., Davis, M., Shovlin, C. L., Ganly, P. S., Haslett, C., and Greening, A. P. (2001). Alveolar macrophage activity and the pulmonary complications of haematopoietic stem cell transplantation. Thorax 56, 941-946. doi:10.1136/thorax.56.12.941

Wiltschke, C., Krainer, M., Nanut, M., Wagner, A., Linkesch, W., and Zielinski, C. C. (1995). In vivo administration of granulocytemacrophage colony-stimulating factor and granulocyte colonystimulating factor increases neutrophil oxidative burst activity. $J$. Interferon Cytokine Res. 15, 249-253. doi:10.1089/jir.1995.15.249

Wingard, J. R., Hsu, J., and Hiemenz, J. W. (2010). Hematopoietic stem cell transplantation: an overview of infection risks and epidemiology. Infect. Dis. Clin. North Am. 24, 257-272. doi:10.1016/j.idc.2010.01.010

Winston, D. J., Territo, M. C., Ho, W. G., Miller, M. J., Gale, R. P., and Golde, D. W. (1982). Alveolar macrophage dysfunction in human bone marrow transplant recipients. Am. J. Med. 73, 859-866. doi:10.1016/0002-9343(82)90777-X
Wright, J. R. (2005). Immunoregulatory functions of surfactant proteins. Nat. Rev. Immunol. 5, 58-68. doi:10.1038/nri1528

Yang, S. (2000). Cyclophosphamide prevents systemic keratinocyte growth factor-induced up-regulation of surfactant protein A after allogeneic transplant in mice. Am. J. Respir. Crit. Care Med. 162, 1884-1890. doi:10.1164/ajrccm.162.5.2002053

Yu, H. (2000). Innate lung defenses and compromised Pseudomonas aeruginosa clearance in the malnourished mouse model of respiratory infections in cystic fibrosis. Infect. Immun. 68, 2142-2147. doi:10.1128/IAI.68.4.21422147.2000

Zimmerli, W., Zarth, A., Gratwohl, A., and Speck, B. (1991). Neutrophil function and pyogenic infections in bone marrow transplant recipients. Blood 77, 393-399.

Conflict of Interest Statement: The authors declare that the research was conducted in the absence of any commercial or financial relationships that could be construed as a potential conflict of interest.

Received: 01 April 2013; accepted: 13 May 2013; published online: 24 May 2013.

Citation: Domingo-Gonzalez $R$ and Moore BB (2013) Defective pulmonary innate immune responses post-stem cell transplantation; review and results from one model system. Front. Immunol. 4:126. doi: 10.3389/fimmu.2013.00126

This article was submitted to Frontiers in Inflammation, a specialty of Frontiers in Immunology.

Copyright (C) 2013 Domingo-Gonzalez and Moore. This is an open-access article distributed under the terms of the Creative Commons Attribution License, which permits use, distribution and reproduction in other forums, provided the original authors and source are credited and subject to any copyright notices concerning any third-party graphics etc. 